\title{
Modelos de atención de los padecimientos: de exclusiones teóricas y articulaciones prácticas
}

\author{
Care illness models: theoretical exclusions \\ and practice articulations
}

Eduardo L. M enéndez 1

1 Centro de Investigaciones y Estudios Superiores en Antropología Social. Calle Juarez 87,

Tlalpan centro, Tlalpan 14000, M éxico DF emenendez1@yahoo.com.mx
Abstract In many Latin American societiesespecially in M exico - there is a diversity of care illness models, which are considered in an isolated and even antagonistic way by state health sector. This happens by living out the observation of individual and group practices which shows the narrow and continual relationship between this models. This paper describes particular relations between biomedicine and selfcare to show the constant transaction process between them. In first place some basic biomedical and selfcare characteristics are considered, then we observe the transaction between them with special attention to drugs prescription and selfmedication. Transaction process is usually ignored by biomedicine and selfmedication process specially criticised by it. We are in the presence of a paradox because biomedicine and state health sector constantly promotes selfcare process which involves selfmedication. W e notice that this takes place without a reflection on articulation and consequences of this transactions on health/illness/care process. We propose to think about this process in view of its intentional use by health services.

Key words Sefcare, Biomedicine, Transactions, Relational approach
Resumen En las sociedades latinoamericanas existen diversos modelos de atención de los padecimientos que son considerados en forma aislada y hasta antagónica por el sector salud, en lugar de observar las estrechas relaciones que se dan entre esos model os a través de las prácticas y representaciones de los sujetos que los utilizan. En este trabajo se describen las relaciones que existen entre la biomedicina y la autoatención, para evidenciar el continuo proceso de transacciones que operan entre las mismas. Primero se describen al gunas características básicas de la biomedicina y de la autoatención, para luego observar las transacciones que existen entre ambas, especialmente a través de la prescripción de fármacos y dela automedicación. Este proceso transaccional tiende a ser ignorado por la biomedicina, que critica los procesos de automedicación, lo que resulta paradojal dado quela biomedicina y sobre todo el sector salud impulsan procesos de autoatención que incluyen la automedicación, sin reflexionar sobre la articulación y sobre las consecuencias que estas transacciones tienen para el proceso salud/enfermedad/atención. Se propone la necesidad no sólo de reflexionar sobre estos procesos transaccionales, sino de utilizarlos intencionalemnte desde el sector salud. Palabras-claves Autoatención, Biomedicina, Transacciones, Enfoque relacional 
Cuando desde una perspectiva antropológica hablamos de modelos de atención, nos referimos no sólo a las actividades de tipo biomédi$\mathrm{co}$, sino a todas aquellas que tienen que ver con la atención de los padecimientos en términos intencionales, es decir que buscan prevenir, dar tratamiento, controlar, aliviar y/o curar un padecimiento determinado, lo cual implica asumir una serie de puntos de partida que contextualizan nuestro análisis de los model os de atención, aclarando que el material empírico que apoya los análisis y conclusiones de este texto surgen de nuestras investigaciones sobre saber médico y alcoholismo ( $M$ enéndez, 1990a; M enéndez y Di Pardo, 1996; 1999) y sobre saber médico y saber popular referidos a diferentes procesos de salud/enfermedad/atención (M enéndez, 1981; 1982; 1984; M enéndez y Ramírez, 1980).

En primer lugar asumimos que en las sociedades latinoamericanas actuales existen muy diferentes formas de atención a la enfermedad que suelen utilizar diversas técnicas diagnósticas, diferentes indicadores para la detección del problema, asi como variadas formas de tratamiento e inclusive diferentes criterios de curación. Pero además de reconocer esta diversidad, cuando nos referimos a estas formas de atención no las pensamos principalmente en términos de eficacia, de eficiencia y/o de calidad, sino en términos de reconocer su existencia, dado que frecuentemente desde la perspectiva del Sector Salud (SS) y de la biomedicina, toda una serie de actividades de atención a los padecimientos es negada, ignorada y/o marginada, pese a ser frecuentemente utilizada por diferentes sectores de la población.

Las diversas formas de atención que actualmente operan en una sociedad determinada tienen que ver con las condiciones religiosas, étnicas, económico/políticas, técnicas y científicas que habrían dado lugar al desarrollo de formas antagónicas o por lo menos fuertemente diferenciadas especialmente entre la biomedicina y la mayoría de las otras formas de atención. Según algunos autores las formas de atención de la medicina tradicional americana se opondrían a determinadas concepciones y hasta valores de la biomedicina, y lo mismo sustentarían representantes de la denominada medicina científica con respecto a mayoría de los usos populares y especial mente de ciertas actividades de autoatención (M enéndez, 1981; 1990b). Si bien dichas diferencias existen, generalmente las mismas tienden a ser registra- das y analizadas por los investigadores a través de las representaciones sociales e ideológicas, y mucho menos en el nivel de las prácticas sociales, es decir de las actividades desarrolladas con respecto a los padecimientos por los grupos que usan las diversas formas de atención, lo cual refuerza una concepción dominante de antagonismos más que de articulaciones transaccionales entre las diferentes formas de atención. $M$ ás aun considero que el reconocimiento de estas oposiciones suele darse sobre todo a través de las representaciones técnicas y sociales de los curadores de las diferentes formas de atención, pero mucho menos a nivel de las prácticas de los conjuntos sociales a través de las cuales observamos una tendencia a integrar las diferentes formas de atención más que a antagonizarlas, excluirlas o negar unas en función de otras.

Lo que domina en las sociedades actuales, dentro de los diferentes conjuntos sociales estratificados que las constituyen y más allá de la situación de clase o de la situación étnica, es lo que se conoce como pluralismo médico, término que refiere a que en nuestras sociedades la mayoría de la población utiliza potencialmente varias formas de atención no sólo para diferentes problemas, sino para un mismo problema de salud.

En las sociedades latinoamericanas, y especialmente en las sociedades capitalistas más desarrolladas se estarían incrementando actualmente las denominadas medicinas alternativas o paralelas, y si bien dicho incremento sería, en cierta medida, una reacción a determinadas características de las orientaciones biomédicas, éste no es sin embargo el factor decisivo, por lo menos respecto de determinados procesos. $\mathrm{Pa}$ ra dar un ejemplo; se suele decir que el desarrollo de ciertas medicinas alternativas es debido en gran medida al tipo de relación médi$\mathrm{co} /$ paciente que ha ido configurando e imponiendo la biomedicina, el cual excluye, niega o subordina la palabra del paciente. Si bien esta afirmación es en parte correcta, debe subrayarse que varias de las medicinas alternativas y de las denominadas "tradicionales" se caracterizan por ser tan asimétricas en términos técnicos o excluyentes de la palabra del paciente como la biomedicina, y algunas mucho más. Para varias de estas medicinas la asimetría - inclusive en el uso de la palabra - es condición necesaria para ejercer la ocupación de atender los padecimientos y por lo tanto de "curar".

El incremento constante de las denominadas medicinas alternativas y la recuperación de 
formas de la medicina popular no constituyen sólo reacciones contra la biomedicina. Si bien no niego la existencia de procesos reactivos hacia la medicina alopática, éstos no constituyen los únicos ni frecuentemente los principales factores de este desarrollo, ya que intervienen una pluralidad de factores incluyendo la industria químico/farmaceútica, que como sabemos constituye uno de los pilares de la intervención y expansión biomédica. Así por ejemplo en el caso de las formas de atención denominadas tradicionales y populares ( $M$ enéndez, 1994), observamos que al gunas de sus actividades han sido resignificadas en sus usos no sólo en el medio rural, sino especialmente en el medio urbano tanto de los países periféricos como desarrollados. Un caso típico es el de la medicina herbolaria que ha sido especialmente impulsada en los últimos veinte años por una parte de la industria químico/farmacéutica, dado el incremento del consumo de estos productos por los sectores sociales de mayores ingresos. En cada sociedad los diferentes grupos utilizan formas específicas de atención tradicional es/populares, pero me interesa subrayar que la mayoría de las mismas están dejando de ser patrimonio exclusivo de determinados sectores sociales, económicos o étnicos.

Otro proceso importante a considerar es la presencia en las sociedades denominadas occidentales de formas de atención a la salud que corresponden a saberes académicos de otros sistemas muy distintos del occidental. Los casos más conocidos son los de la acupuntura y de la digitopuntura, pero debe subrayarse que en varios países europeos y latinoamericanos se han asentado y desarrollado la medicina mandarina o la medicina ayurvédica en contextos donde previamente no existían estas tradiciones académicas. Si bien una parte de este desarrollo se debe a procesos migratorios de masa, que implican el asentamiento no sólo de trabajadores migrantes, sino también de sus sistemas de atención; en otros casos son debidos a un proceso de apropiación generado por determinados sectores sociales de los propios países "occidentales".

Estos y otros procesos han impulsado una constante diversidad de las formas de atención a la enfermedad, que por supuesto adquiere una dinámica y diferenciación específica en cada contexto. Ahora si bien casi todas estas formas de atención, incluida la biomedicina, se preocupan por la salud, dado que en el caso de la biomedicina por ejemplo busca prevenir y educar para la salud, y otras formas de atención promueven el desarrollo de una salud equilibrada o inclusive se propone la búsqueda de mecanismos para impulsar una salud positiva; lo real es que la casi totalidad de las actividades de las diversas formas de atención actúan básicamente respecto de los padecimientos y enfermedades y no sobre la promoción de salud. Y esto no sólo porque lo proponen e impulsan los curadores, sino porque lo solicitan los sujetos y grupos sociales, ya que éstos demandan acciones sobre sus padeceres más que sobre su salud. Lo señalado no ignora que, especialmente en las sociedades capitalistas de más alto grado de desarrollo, se incrementa la población que realiza diferentes tipos de acciones en busca de mejorar y/o promover su propio estado de salud a nivel individual, aunque frecuentemente a través de una noción sumamente medicalizada del mismo pese al uso de formas alternativas.

\section{Los conjuntos sociales como eje de la atención de los padecimientos}

La identificación y descripción de las formas de atención la iniciamos a través de lo que hacen y usan los sujetos y grupos sociales para atender sus padecimientos, y no a partir de los curadores biomédicos, tradicionales 0 alternativos. En términos metodológicos iniciamos la descripción a través de los sujetos y los conjuntos sociales porque a partir de los mismos, especialmente de la trayectoria de la "carrera del enfermo" o "carrera del paciente" podemos identificar todas 0, por lo menos, la mayoría de las formas de atención que intervienen en un contexto determinado, lo cual sería difícil de obtener por muy diversas razones - si partimos inicialmente de los curadores. Pero además, a través de los conjuntos social es podemos observar el uso articulado de las diferentes formas que usa cada grupo y no los usos excluyentes. Si nosotros partiéramos de cada curador, de cada forma de atención, lo frecuente sería la ignorancia o exclusión de las otras formas de atención o un reconocimiento crítico y frecuentemente estigmatizado de las mismas, así como la tendencia a focalizar la descripción en la forma específica que cada curador representa. Pero además es a través de las perspectivas y de los usos de los diferentes actores significativos ( $M$ enéndez, 1997) que podemos detectar la variedad de articulaciones que estos realizan respecto de las 
diferentes formas de atención que potencialmente pueden utilizar en un contexto determinado, porque la mayoría de esas articulaciones se generan a través de las acciones que los sujetos y grupos realizan para poder reducir o solucionar sus problemas.

Considero que si el sector salud quiere conocer y/o implementar el sistema de atención real que utilizan los sujetos y conjuntos sociales, debería identificar, describir y analizar las diferentes formas de atención que los conjuntos sociales manejan respecto de la variedad de padeceres reales e imagi narios que reconocen como afectando su salud. Por supuesto que esto no supone que reduzcamos la identificación de los padeceres ni de las formas de atención sólo a los que reconocen los conjuntos sociales, sino que este es el punto de partida para establecer la existencia de los padeceres y de las formas de atención que los grupos no sólo reconocen sino que sobre todo utilizan.

Esta aproximación implicaría detectar y construir los perfiles epídemiológicos y las estrategias de atención que desarrollan en forma particular el saber biomédico, el saber de los curadores tradicionales, el saber de los curadores alternativos y/o el saber de los grupos sociales, lo cual posibilitaría observar no sólo las convergencias y divergencias en la construcción del perfil epidemiológico dominante, sino el tipo de atención utilizada en situaciones específicas. Este tipo de aproximación, que aplicamos en el análisis de comunidades rurales y urbanas en Yucatán ( M enéndez, 1981; M enéndez y Ramirez, 1980) y en Guanajuato ( $M$ enéndez, 1984) contribuiría a producir una epidemiologia de los comportamientos respecto del proceso s/e/a (salud/enfermedad/atención), que posibilitaría comprender la racionalidad de las acciones desarrolladas por los sujetos y grupos sociales, asi como también la racionalidad de los diferentes tipos de curadores, lo cual permitiría desarrollar estrategias que articulen dichas racionalidades.

Procesos sociales, económicos y culturales posibilitan el desarrollo de diferentes formas de atención a partir de las necesidades y posibilidades de los diferentes conjuntos sociales. Y cuando decimos esto pensamos en las estrategias de supervivencia desarrolladas por personas ubicadas en situación de marginalidad y extrema pobreza, o que están cayendo en situación de pobreza; hasta sujetos que dada su búsqueda de una suerte de eterna juventud frecuentemente homologada a salud, encuentran en ciertas prácticas la posibilidad imaginaria y momentánea de lograrla; pasando por la adhesión a prácticas religiosas que proveerían de un "equilibrio" al sujeto que va más allá de la enfermedad inmediata que padece. Las carencias económicas, la existencia de enfermedades incurables o si se prefiere todavía no curables, asi como la búsqueda de soluciones a pesares existencial es conducen a la búsqueda y frecuente creación o resignificación de formas de atención. Frente a determinadas formas de alcoholismo para las cuales la biomedicina tiene una eficacia limitada, los propios conjuntos sociales desarrollaron grupos de autoayuda como Alcohólicos Anónimos (AA), forma de atención que evidencia la mayor eficacia comparativa con cualquier otro tipo de atención específica respecto de este problema. Pero otros grupos han creado respecto del "alcoholismo" otras estrategias como son "Ios juramentos a la virgen" en el caso de M éxico ( $M$ enéndez y Di Pardo, 1996) o el uso de la brujería en el suroeste de los EEUU (Trotter y Chavira, 1981), que también tienen resultados en el control del consumo patológico de alcohol, y en la diminución de los daños generados por dicho consumo.

Si nosotros partimos de los comportamientos de los sujetos y grupos respecto de sus padeceres, y cuando propongo esto pienso en conjuntos sociales estratificados $y / 0$ diferenciados a través de condiciones ocupacionales, económicas, étnicas, religiosas, etc., que operan en diferentes contextos latinoamericanos, nos encontramos con que los mismos utilizarían potencialmente las siguientes formas de atención: a) de tipo biomédica referidas a médicos del primer nivel de atención y del nivel de especialidades para padecimientos físicos y mentales que la biomedicina reconoce como enfermedades. Estas se expresan a través de instituciones oficiales y privadas. Dentro de esta deben reconocerse formas antiguas, y comparativamente marginales en la biomedicina como son la medicina naturista, la balneoterapia o la homeopatía, asi como la inclusión de formas devenidas de otras concepciones como es el caso de la quiropracia. Aquí también deben incluirse las diferentes formas de psicoterapia individual, grupal y comunitaria gestadas por lo menos en parte desde la biomedicina;

b) detipo "popular" $y$ "tradicional" expresadas también a través de curadores especializados como hueseros, culebreros, brujos, curanderos, espiritualistas, yerberos, shamanes, etc. Aquí debe incluirse el papel curativo de ciertos san- 
tos o figuras religiosas tanto cristianas como de otros cultos, asi como el desarrollo de actividades curativas a través de grupos como los pentecostales o los carismáticos;

c) alternativas, paralelas o new age que incluyen a sanadores, bioenergéticos, nuevas religiones curativas de tipo comunitario, etc.;

d) devenidas de otras tradiciones médicas académicas: acupuntura, medicina ayurvedica, medicina mandarina, etc.;

e) centradas en la autoayuda: Alcohólicos Anónimos, Neuróticos Anónimos, Clubes de Diabéticos, padres de niños con síndrome de Down, etc., cuya característica básica radica en que están organizadas y orientadas por las personas que padecen o co/padecen algún tipo de problema.

Esta clasificación de las formas de atención, que podría ampliarse y/o modificarse, no supone que las consideremos como formas estáticas y aisladas cada una en si misma, dado que asumimos la existencia de un proceso dinámico entre las actividades devenidas de diferentes formas de atención; es decir que las mismas no funcionan siempre excluyentemente sino también a través de relaciones entre dos o más formas de atención. Dicha dinámica opera en por lo menos dos niveles, el que refiere a las relaciones establecidas entre las diversas formas de atención a través de uno de los diferentes operadores de las mismas; y así vemos como la biomedicina por lo menos en determinados contextos se apropia de la acupuntura o de la quiropracia, y en otros retoma la tradición herbolaria o incluye grupos de $\mathrm{N}$ euróticos A nónimos como parte de los tratamientos. Por lo cual se genera algún tipo de articulación entre diferentes formas de atención, inclusive entre al gunas que en determinados momentos aparecían como antagónicas como es el caso de la actitud biomédica inicial hacia Alcohólicos Anónimos, ya que en América Latina, y en particular en M éxico, la biomedicina y el sector salud rechazaron inicialmente en forma tácita o explícita a los grupos de Alcohólicos Anónimos; algunos epidemiólogos y psiquiatras sostenían que dichos grupos de AA no se expandirían por Latinoamérica debido a razones de tipo cultural, especialmente religiosas. Sin embargo a partir de la década de los 60', pero sobre todo de los 70' se genera una notable expansión de estos grupos, que condujo a que países como Honduras y $M$ éxico sean de los que tienen un mayor número de grupos a nivel mundial ( $M$ enéndez, 1990; M enéndez y Di Pardo, 1996; 1999).
El otro nivel refiere a la integración de dos o más formas de atención por sujetos y grupos que tienen algún padecimiento, lo cual puede ser sobre todo observado a través de la denominada carrera de enfermo, y constituyéndose este tipo de articulación en el más frecuente, dinámico y expandido.

Por supuesto que otras fuerzas sociales operan en este proceso de relación entre las diferentes formas de atención de la enfermedad, como es el caso de ciertas organizaciones no gubernamentales en el campo de la salud reproductiva o el de la propia industria químico/farmacéutica impulsando cada vez más los medicamentos de origen herbolario. Pero desde nuestro punto de vista son las actividades impulsadas por los sujetos y grupos sociales las que generan la mayoría de las articulaciones entre las diversas formas de atención a través de sus usos, y superando frecuentemente la supuesta o real diferencia o incompatibilidad que puede existir entre las mismas, dado que dichas incompatibilidades y diferencias son secundarizadas por la búsqueda de una solución pragmática a sus problemas. Lo cual no niega que haya diferencias significativas y hasta incompatibilidades entre las diferentes formas de pensar y actuar sobre el proceso s/e/a, pero dichas diferencias deben ser observadas siempre en las prácticas sociales y técnicas, dado que es a través de éllas que podremos evidenciar las diferencias, pero también el uso articulado de, por lo menos, una parte de las mismas. Dichas articulaciones se desarrollan a través de diferentes dinámicas transaccional es dentro de relaciones de hegemonía/subalternidad ( $M$ enéndez, 1981; 1983; 1984). Si bien, como lo señalamos, al gunas articulaciones se generan a través de los propios curadores, estos tratan de mantener su propia identidad como curadores, y desde esa perspectiva más que articular se genera una apropiación de técnicas pero manteniendo la diferencia, hegemonía y/o exclusión a través de seguir proponiendo su forma de curar como la más idónea. Esta es la manera dominante de actuar de la biomedicina, que si bien en gran medida puede ser analizada en términos de un mercado competitivo de saberes y técnicas, no sólo por supuesto es una cuestión de mercado, sino que incluye procesos ideológicos, sociales y técnicos que tienen que ver con el mantenimiento y desarrollo de la identidad profesional y de su hegemonía.

Este proceso podemos observarlo en uno de los campos menos legitimados dentro del saber 
biomédico, es decir el referido a la salud mental, el que actual mente se caracterizaría por una actitud ecléctica según la cual y en función del objetivo terapeútico, la psiquiatría utilizaría todas aquellas estrategias y orientaciones que demuestran cierto grado de eficacia, pasando por lo tanto a segundo plano la fundamentación teórica de las caracteristicas diferenciales de cada una de las mismas. Pero debe subrayarse que sólo una pequeña parte de la psiquiatría - y subrayo lo de psiquiatría - recurre a formas de atención desarrolladas desde perspectivas no médicas, ya que el eclecticismo se reduce a las diferentes técnicas desarrolladas desde la biomedicina y campos afines. Esto no ignora por supuesto la existencia de numerosas experiencias que han incluido desde técnicas shamánicas hasta rituales sociales urbanos de curación en varios países latinoamericanos, pero esta no ha sido la línea dominante especialmente en el caso mexicano (M enéndez y Di Pardo, 1996; 1999).

El proceso de apropiación y eclecticismo podemos observarlo no sólo a través de la biomedicina sino de otras formas de atención; en América Latina hay un proceso constante según el cual una parte de los curadores populares y tradicionales además de prescribir y/o realizar sus tratamientos tradicionales, recetan también antibióticos o vitaminas como parte de su forma de atención. En el caso de las parteras Ilamadas empíricas se observa la utilización de técnicas de inducción del parto de tipo biomédico. Debe subrayarse que este proceso de apropiación obedece a varias dinámicas entre las cuales subrayo dos: la desarrollada a partir de los propios curadores en busca de mayor eficacia, lo cual conduce, en determinados casos, a que las medicinas generadas por la industria químico/farmacéutica sean incluidas y usadas en las concepciones culturales tradicionales como las de la oposición y complementación entre lo frío y lo caliente como ocurre con el uso de las aspirinas, penicilina o alka-zelzer en numerosos grupos étnicos mexicanos. Y otra impulsada por la propia biomedicina o si se prefiere por el sector salud a través de los programas de atención primaria que viene aplicando desde por lo menos los años 20' (M enéndez, 1981). De tal manera que por ejemplo en M éxico fue el sector salud el que enseñó a parte de la población de las comunidades rurales a dar inyecciones dado que no existían recursos humanos locales para hacerlo, y parte de este personal que aprendió a inyectar eran cu- radores tradicionales; fue el sector salud el que adiestró a parteras empíricas de tal manera que estas utilizaron una síntesis de el ementos tradicionales y biomédicos; fue el sector salud el que enseñó a sujetos de las comunidades a cortar nódulos de personas con oncocercosis o que seleccionó personas de la comunidad como agentes de salud. Fue el sector salud y un número cada vez más amplio de ONG las que formaron y siguen formando cientos de promotores de salud que suelen utilizar una mezcla de técnicas populares y biomédicas.

Este proceso complejo, dinámico y diferenciado podemos observarlo y detectarlo de conjunto sobre todo si lo registramos a través de las acciones de los grupos sociales, dado que desde la perspectiva de las diferentes formas de atender - y no sólo de la biomedicina - sólo registraremos una parte de dichas formas de atención y generalmente en forma no relacionada. Desde las diferentes formas de atención, y especialmente desde el saber e instituciones biomédicas, sólo se tenderá a reconocer al gunas de las formas de atención, y no las más diversas y a veces impensables actividades curativas 0 sanadoras. Pero además tiende a generarse una visión estigmatizada y excluyente de por lo menos al gunas formas de atención, colocando el eje de la eficacia, de la eficiencia y de la legitimidad exclusivamente sobre el propio quehacer y no sobre el conjunto de las formas de atención. Este proceso, y lo subrayo, también ocurre con las otras formas de atención que no fundamentan su legitimidad e identidad en la racionalidad científica sino en la religiosa y/o étnica, proponiendo una eficacia comparativa inherente al uso exclusivo de estas dimensiones.

Si el eje lo colocamos en los diferentes conjuntos sociales no sólo registraremos todas o por lo menos la mayoría de las formas de atención que se usan realmente, sino que no tendremos una visión unilateral de las formas de atención que pretenden su exclusividad a través de lo científico, de lo religioso o de lo étnico, dado que las registramos a través de los diferentes puntos de vista que operan en una comunidad y que incluyen no sólo las perspectivas de la población estratificada, sino la de los diferentes tipos de curadores ( $M$ enéndez, 1990b; 1997). Pero el aspecto central, que luego desarrollaremos, es que los sujetos y grupos sociales constituyen el agente que no sólo usa las diferentes formas de atención, que las sintetiza, articula, mezcla o yuxtapone, sino que es el agente que 
reconstituye y organiza una parte de estas formas de atención en actividades de "autoatención", dado que la autoatención constituye no sólo la forma de atención más constante sino el principal núcleo de articulación práctica de las diferentes formas de atención, la mayoría de las cuales no puede funcionar completamente sino se articula con el proceso de autoatención. Este señalamiento es obvio, pero tiende a ser no sólo olvidado, sino excluido del analisis de los servicios de salud. U na cosa es hablar de convalescencia y otra asumir que el papel decisivo en gran parte de las actividades de convalescencia están a cargo del sujeto y su grupo a través de acciones de autoatención.

Un análisis integral de las formas de atención que operan en un contexto determinado supondría obtener el perfil epidemiológico de los padecimientos dominantes y sus formas de atención en una comunidad determinada, según son formulados por los diferentes curadores y por los conjuntos sociales ( $M$ enéndez, 1984; M enéndez y Ramirez, 1980). Esta información nos daría algo así como un diagnóstico de situación sobre como atiende la gente realmente sus padeceres, incluída la articulación de las diferentes formas de atención generadas por la población, y más allá de los antagonismos existentes a nivel es profesionales e institucionales en términos económicos, técnicos e ideológicos. En varios trabajos realizados en diferentes contextos mexicanos ( $M$ enéndez y Ramirez, 1980; M enéndez, 1984; 1990b; O sorio, 1994) se describe como, durante la carrera del enfermo, los sujetos demandan inicialmente un tipo de atención en función del diagnóstico presuntivo que manejan y de otros factores como la accesibilidad física y económica a las diferentes formas de atención que operan en su contexto de vida, pero si dicha atención no resulta eficaz la reemplazan rapidamente por la atención de otro tipo de curador, implicando este cambio una transformación en el diagnóstico y tratamiento. Este proceso puede agotarse en esta segunda instancia o dar lugar a la demanda de otras formas de atención, que puede implicar una nueva demanda de atención a los primeros curadores consultados. Los indicadores diagnósticos que los grupos manejan posibilitan una articulación práctico/ideologica entre las diferentes formas de atención estableciendo una conexión entre las mismas a través de la carrera del enfermo.

Este tipo de aproximación epidemiológi$\mathrm{ca}$ - que denominamos sociocultural - posibi- litaría además observar cuales son las formas de atención más usadas y las que tienen mayor eficacia para abatir, controlar o disminuir determinados daños en términos reales o imaginarios. Al igual que también podríamos registrar cuales son los factores de tipo económico, técnico e ideológico que se oponen o facilitan la articulación de las diferentes formas de atención, a través de las prácticas cotidianas de los conjuntos sociales.

Pero en este trabajo no podemos desarroIlar el análisis integral de las diferentes formas de atención, sino que a modo de ejemplo nos concentraremos en los que consideramos las dos formas dominantes de atención a los padecimientos en un contexto como el mexicano actual, me refiero a la biomédica y a la autoatención; asumiendo que en la sociedad mexicana encontraremos distintas formas de articulación entre biomedicina y autoatención en función de las características socioeconómicas, étnicas, religiosas, educacionales, de localización, etc. de los diferentes grupos y sujetos sociales. Lo que haremos primero es describir al gunas características básicas de la biomedicina, haciendo hincapié en aquellas que limitan la posibilidad de una articulación mayor y más eficaz con la autoatención, y luego haremos lo mismo con la autoatención para concluir proponiendo algunos mecanismos de articulación posibles.

\section{Biomedicina: algunos rasgos y limitaciones}

En principio recordemos que la biomedicina en tanto institución y proceso social se caracteriza por su constante aunque intermitente modificación y cambio y no por su inmovilidad, y cuando señalo esto no me refiero sólo a cambios técnicos y científicos, sino a cambios en sus formas dominantes de organizarse e intervenir no sólo técnica sino económica, social y profesionalmente. Por lo cual el análisis que estamos realizando en este texto no refiere a la biomedicina que se practicaba en 1850, en 1920 o 1950, sino a las tendencias que se desarrollan desde los 60' y 70' hasta la actualidad.

Quiero subrayar que para ciertas miradas a-históricas, estos cambios - o por lo menos algunos de éllos - suelen ser leídos en términos de crisis, generando en al gunos casos la idea que la biomedicina estaría en una situación de crisis permanente; más aun para al gunas ten- 
dencias habría un casi constante derrumbamiento de la misma, augurándose su reemplazo más o menos inmediato por algunas formas de atención "alternativas". Otras tendencias biomédicas por el contrario están en una suerte de exitismo cientificista, que sólo concibe el cambio en términos de progeso técnico más o menos infinito, pero que demuestra escasa sensibilidad para detectar y explicar los cambios institucionales, culturales y económico/políticos que afectan el saber médico. Estas orientaciones - y por supuesto otras - simplemente las señalamos pero sin analizarlas, ya que lo que lo que buscamos es, por una parte, subrayar que los cambios y modificaciones no tienen que ver necesariamente con crisis ni con progresos tecnológicos, y por otra que uno de los aspectos más significativos de las modificaciones y cambios que observamos en biomedicina, son las que se expresan a través de su proceso de expansión. En los contextos desarrollados y sudesarrollados denominados occidentales, y pese al incremento de medicinas paralelas y alternativas, la forma de atención que más se expande directa o indirectamente sigue siendo la biomédicina. Lo cual además nos conduce a reconocer, que si bien en algunos países occidentales se están estableciendo y desarrollando actividades correspondientes a otras tradiciones médicas académicas, sin embargo en los países que han originado dichas tradiciones como Japón, India o China está expandiéndose e inclusive pasando a ser hegemónica la biomedicina, siendo ésta la que subalterniza y/o desplaza a las medicinas académicas locales.

Es el conjunto de estos procesos, que alcanza su expresión más notoria en la expansión del consumo de medicamentos producidos por la industria químico/farmaceútica, el que respalda nuestro análisis. En países como M éxico dicha industria en forma directa 0 a través del sector salud ha conseguido colocar algunos de sus productos en los lugares más remotos y aislados del país siendo actualmente parte de las estrategias de atención de los diversos grupos étnicos mexicanos. Pese a la evidencia de esta tendencia se prefiere afirmar la pérdida de importancia de la biomedicina a través de lo que ocurre en algunos campos como el psiquiátrico, dado que en varios países se observa un constante descenso en el número y/o porcentaje de psiquiatras. En los EEUU desde hace unos veinte años decrece constantemente el número de estudiantes de medicina que eligen la orientación psiquiátrica, lo cual indica cambios en la orientación profesional de la biomedicina pero sin que éllo implique la reducción de la expansión de la misma.

Lo señalado no significa negar que existen situaciones conflictivas, cuestionamientos e inclusive desarrollos de formas de atención que parcialmente reemplazan o complementan a la biomedicina, sino que significa asumir la existencia de procesos de cambio que afectan a las instituciones y profesiones, incluido el sector salud y respecto de los cuales se generan modificaciones que deben ser analizadas en su real significación. Tampoco negamos que algunos de estos procesos adquieren el carácter de crisis, pero para asumirlo habría que definir que se entiende por crisis, cuales son sus indicadores y cuales son sus consecuencias tanto para la biomedicina como para los conjuntos sociales. Desde esta perspectiva frente a situaciones de conflicto y/o de cambio o - si se pretende - de crisis, la biomedicina hasta ahora ha encontrado siempre "soluciones" que siguen asegurando su expansión, y donde reiteradamente el eje de su impulso y justificación está centrado en la biologización de su enfoque profesional y técnico. Posiblemente la mayor crisis operada dentro de la biomedicina, por lo menos a nivel de los críticos, se dio entre mediados de los 60' y fines de los 70'. Las criticas iban dirigidas hacia la pérdida de eficacia de la biomedicina, hacia el desarrollo de una relación médico/paciente que no sólo negaba la sujetividad del paciente sino que incrementaba la ineficacia curativa, al desarrollo de una biomedicina centrada en lo curativo y excluyente de lo preventivo, en un énfasis de las actividades asistenciales que incrementaba constantemente el costo económico de la atención de la enfermedad, a las constantes situaciones donde se registraban transgresiones a la ética médica, etc., etc., etc. Varias de estas criticas están a la base de las propuestas de Atención Primaria I ntegral desarrolladas desde los 60', pero que luego de un primer impacto redujeron las expectativas de sus propuestas, asi como disminuyeron también las críticas. Pero en los $80^{\prime}$ y sobre todo en los $90^{\prime}$ reaparecen las críticas, tal vez menos ideologizadas que en los 60', denunciando otra vez la ineficacia de la biomedicina puesta de relieve en el retorno de la morbimortalidad por tuberculosis broncopulmonar, cólera o dengue, en la imposibilidad de curar la mayoría de las enfermedades crónicas ya que hasta ahora sólo es posible controlarlas; en el incremento constante de la desnutrición, en la persistencia de 
problemas éticos, etc., etc., etc. Pero nuevamente estas críticas están disminuyendo, y el eje estrutucturador sigue estando colocado en el biologicismo de la manera de pensar y actuar biomédica. La biomedicina sigue depositando sus expectativas en el desarrollo de una investigación biomédica que da lugar al surgimiento de explicaciones biológicas de los principales padecimientos y de soluciones basadas en la producción de fármacos específicos, así como incide en la constante biologización de las representaciones sociales del proceso s/e/a (M enéndez, 2002).

Más allá de críticas y crisis, lo que observamos es una continua expansión de la biomedicina que afecta su relación con las otras formas de atención. Dicha expansión se caracteriza por un proceso de continuidad/discontinuidad, donde la continuidad está dada por el constante aunque intermitente proceso de expansión basado en la investigación biomédica, en la producción farmacológica y en la medicalización no sólo de padeceres sino de comportamientos; y la discontinuidad por las orientaciones críticas surgidas al interior y fuera de la propia biomedicina, así como por las actividades y representaciones impulsadas por las otras formas de atención y especialmente por las prácticas de los diferentes conjuntos sociales para asegurar la atención y solución real y/o imaginaria de sus padecimientos.

Este proceso de expansión se da básicamente en dos niveles; por una parte a través de las actividades profesionales que se realizan y que refiere a los niveles de cobertura de atención alcanzados, al número de profesionales, al número de camas de hospitalización, al número de partos atendidos institucionalmente, al número de cesáreas, a la cobertura de inmunización, etc., etc., etc., comparados - o no - con los indicadores de las otras formas de atención. Estas tendencias han sido y son estudiadas para posibilitar la planificación de los recursos, para el evar la calidad de los servicios o para reducir costos, pero también pueden ser utilizadas como indicador que puede evidenciar el desplazamiento o suplantación de otras formas de atención por la biomedicina, o viceversa.

Pero además la expansión opera a través de lo que se denomina proceso de medicalización, es decir un proceso que implica convertir en enfermedad toda una serie de episodios vitales que son parte de los comportamientos de la vida cotidiana de los sujetos, y que pasan a ser explicados y tratados como enfermedades cuan- do previamente sólo eran aconteceres ciudadanos. Este proceso implica no sólo que los sujetos y grupos vayan asumiendo dichos aconteceres ciudadanos en términos de enfermedad y no de lo que tradicionalmente han sido, es decir conflictos y padeceres, sino que pasen a explicarlos y atenderlos, en gran medida a través de técnicas y concepciones biomédicas. Esta medicalización supone no sólo convertir en problema de salud determinadas situaciones cotidianas - como fue y es el caso de la hiperkinesis infantil (Conrad, 1976; Conrad y Schneider, 1980), sino convertir en problema quirúrgico la situación de parto a través de la generalización de la cesárea en países como M éxico, donde un alto porcentaje de los partos en las instituciones oficiales y privadas se hacen a través de cesáreas innecesarias (Cárdenas, 2000). Si bien respecto del proceso de medicalización existe actualmente una concepción menos unilateral y mecanicista que la dominante en los 60 ' y 70', que inclusive ha conducido a algunos autores a negar dicho proceso, no cabe duda que el mismo no sólo existió sino que sigue vigente. Lo que las investigaciones y reflexiones actuales han cuestionado es la visión omnipotente y unilateral con que eran - y todavia son observados por algunos autores - estos procesos, según la cual la biomedicina podía imponer casi sin modificaciones y oposiciones sus maneras de explicar y atender los padeceres, y sin tomar en cuentra las resignificaciones, reacciones y acciones de los sujetos y grupos sobre los cuales actuaba.

Son estas tendencias las que operan en las relaciones de la biomedicina con los conjuntos sociales y con los otros saberes médicos; siendo especialmente la medicina alopática la que establece las condiciones técnicas, sociales eideológicas dentro de las cuales se desarrollan las relaciones con los otros saberes. El análisis de al gunas de las características estructurales de la biomedicina nos permitirá observar lo que estamos señalando. La biomedicina actual se caracteriza por una serie de rasgos técnicos, profesionales, ocupacionales, sociales e ideológicos que hemos analizado en varios trabajos ( $\mathrm{Me}$ néndez, 1978; 1979; 1981; 1983; 1984; 1990a; M enéndez y Di Pardo, 1996; 1999), y que no sólo expresan la orientación dominante de la medicina alopática, sino que algunas de dichas características evidencian el tipo de relación que la biomedicina establece con los conjuntos sociales estratificados asi como con las otras formas de atención. 
A nivel de lo que denomino M odelo $M$ édico Hegemónico (M M H) he descripto y analizado alrededor de unas treinta características estructurales, de las cuales sólo comentaré algunas que nos permitan especialmente observar ciertas tendencias que orientan las relaciones de la biomedicina con las actividades de autoatención, aclarando que cuando hablo de $\mathrm{MMH}$ referido a la medicina alopática, lo hago en términos de una construcción metodológica manejada en un alto nivel de abstracción, de tal manera que como todo modelo constituye un instrumento heurístico para la indagación de la realidad, pero no constituye la realidad (M enéndez, 1990a). Es como construcción metodológica que considero que las principales caracteristicas del M M H son las siguientes: biologismo, a-sociabilidad, a-historicidad, aculturalismo, individualismo, eficacia pragmática, orientación curativa, relación médico/paciente asimétrica y subordinada, exclusión del saber del paciente, profesionalización formalizada, identificación ideológica con la racionalidad científica, la salud/enfermedad como mercancía, tendencia a la medicalización de los problemas, tendencia a la escisión entre teoría y práctica (M enéndez, 1978; 1981; 1983; 1990a).

El rasgo estructural dominante de la biomedicina es el biologicismo por lo menos a nivel ideológico/técnico, dado que es el factor que no sólo refiere a la fundamentación científica del diagnóstico y del tratamiento, sino que constituyen el principal criterio de diferenciación con las otras formas de atención. Si bien el saber biomédico, especialmente en algunas de sus especialidades y orientaciones, toma en cuenta los niveles psicológicos y sociales de los padecimientos, la biomedicina en cuanto institución tiende a subordinarlos o excluirlos respecto de la dimensión biológica. La dimensión biológica no es meramente un principio de identificación y diferenciación profesional, sino que es el núcleo de la formación profesional del médico. El aprendizaje se hace a partir de contenidos biológicos, donde los procesos sociales, culturales y psicológicos son anecdóticos, y donde no hay información sistemática sobre otras formas de atención. Es de la investigación biológica, bioquímica, genética que la biomedicina extrae sus principales explicaciones y sobre todo sus principales instrumentos de curación. Esta afirmación no ignora la importancia del trabajo médico cotidiano, incluída la investigación clínica, pero el mismo aparece como un campo aplicativo y subordinado al campo de investigación que es el que genera las explicaciones y el tipo de fármaco específico a utilizar por los clínicos. El paso a primer plano de la investigación genética en los últimos veinte años ha reforzado aun más esta tendencia ( $M$ enéndez, 2002).

Quiero subrayar, para evitar equívocos, que al señalar el peso del biologicismo no ignoro obviamente sus aportes; ni tampoco niego el uso por parte del personal de salud de relaciones personales, incluida la dimensión psicológica, no sólo en la relación afectiva con el paciente sino en la estrategia curativa y hasta diagnóstica, pero estas habilidades personales aparecen como secundarias desde la perspectiva de la biomedicina en términos de institución y de formación profesional.

El biologicismo inherente a la ideología médica es uno de los principales factores de exclusión funcional de los procesos y factores históricos, sociales y culturales respecto del proceso salud/enfermedad y de las otras formas de atención consideradas por la biomedicina como formas culturales, y en consecuencia excluidas o por lo menos subalternizadas. Pero un aspecto importante a recordar, es que el médico no tiene formación profesional sobre los factores y pocesos sociales y culturales que inciden en el desarrollo y mantenimiento de los padecimientos; salvo en el campo salubrista donde puede haber formación sistemática, el resto del personal de salud incluye estos aspectos, si es que le interesa, a través de sus posibilidades y habilidades personales y no de una formación técnica específica. No obstante no es el factor que más me interesa analizar, ya que para mi el más decisivo es observar si el personal de salud considera estos factores como importantes de manejar a nivel de su acto médico, y de ser importantes ¿cómo los utilizaría para contribuir a aliviar, controlar o curar el padecimiento? Y frente a este interrogante debemos reconocer que en el nivel de la intervención la mayoría de los médicos dejan de lado dichos aspectos; una cosa es reconocer que la situación de extrema pobreza y marginalidad incide en la desnutrición, y otra poder operar con dichos factores en la intervención clínica más allá de un proceso de rehabilitación que no puede evitar la recidiva, a menos que existan programas de alimentación complementaria. Prácticamente ningun médico ignora esta influencia, aunque una parte prefiera hablar de malnutrición y subrayar ciertos aspectos de ésta más que los de desnutrición, lo cual en función de lo que venimos 
desarrollando es sin embargo secundario. $\mathrm{Si}$ bien el personal médico puede asumir la importancia de factores como la extrema pobreza en el desarrollo y mantenimiento de problemas de salud, a nivel técnico e institucional su manejo de estos aspectos es, por decirlo suavemente, limitado. Y esta limitación la podemos observar a través de los aspectos más decisivos del trabajo médico.

Desde por lo menos la década de los 50' diferentes tendencias de la psicología, de la sociología, de la antropología y de la misma biomedicina vienen señalando la importancia de la relación médico/paciente, para el diagnóstico y para el tratamiento, y en consecuencia la necesidad de mejorarla, de hacerla más simétrica, de incluir no sólo la palabra del paciente sino sus referencias socioculturales, dado que las mismas tienden a ser excluídas por la mayoría de los médicos. De allí que parte del mejoramiento de la calidad de los servicios médicos está depositada justamente en la modificación de aspectos de la consulta. De esto son concientes gran parte de los médicos, y reiteradamente se propone la necesidad de mejorar dicha relación, incluyendo dar más tiempo a la palabra del paciente. Dentro del campo antropológico se ha desarrollado una corriente liderada por médicos de formación antropológica que desdela década de los $70^{\prime}$ y sobre todo desde los $80^{\prime}$ vienen proponiendo la necesidad de que el mé dico no sólo posibilite que el paciente narre su enfermedad, sino que el facultativo aprenda a decodificar cultural y medicamente el significado de dichas narrativas. Esta propuesta tiene sus dos principales centros de influencia en las escuelas de M edicina de $\mathrm{H}$ arvard y de Berkeley donde trabajan respectivamente Kleinman (1988a; 1988b) y Good (1994; Good y Del Vecchio Good, 1993), que en el caso de este último ha implicado el desarrollo de un programa especial de formación de médicos dentro de esta concepción. Estos, pero también autores pertenecientes a otras tendencias como la denominada antropologia médica crítica, proponen la articulación de las distintas formas de atención como parte de la intervención biomédica o si se prefiere de los servicios de salud.

Pero debemos recordar que, más allá de algunas particularidades, esta propuesta reitera lo señalado por diferentes corrientes desde por lo menos la década de los 20' ( $M$ enéndez, 2002), y subrayo lo dela reiteración, porque dicha propuesta opera más en el plano de la reflexión teórica y de las experiencias universita- rias que en el plano de los servicios de salud, los cuales - por lo menos en algunos aspectos significativos - suelen orientarse en un sentido inverso de lo recomendado por los que analizan y reflexionan sobre la relación médico/paciente y su papel dentro de los servicios de salud oficiales y/o privados. Si observamos sistemas de salud como el británico o el mexicano ¿qué es lo que econtramos? Encontramos que pese a reconocer las criticas señaladas respecto de las características dominantes en la relación médico/paciente y la necesidad de revertir la orientación de los servicios, lo que se desarroIla en los hechos es una tendencia a reducir cada vez más el tiempo de la relación médico/paciente y especialmente el tiempo dado a la palabra del paciente. Es decir se potencian la tendencia histórica de la biomedicina para establecer una relación asimétrica y las dinámicas institucionales actuales que tienden a reforzar dicha orientación de la biomedicina más allá de los discursos y reflexiones de los científicos sociales y de las propias autoridades sanitarias. Asi por ejemplo en el Instituto M exicano del Seguro Social (IMSS), que da atención a cerca del $50 \%$ de la población mexicana, la media actual del tiempo de consulta es de cinco minutos ( $M$ enéndez, 2000). Estas conclusiones no ignoran que existen tendencias que proponen otras formas de relación médico/paciente, o por lo menos modalidades que posibilitan una mayor expresión de la palabra y de las acciones del paciente.

La relación médico/paciente se caracteriza especialmente en el primer nivel de atención pero también a nivel de especialidades por la duración cada vez menor del tiempo de la consulta, por reducir cada vez más la palabra del paciente, pero también por reducir cada vez más la palabra del propio médico. En la mayoría de las instituciones médicas oficiales ya no se realizan historias clínicas en el primer nivel de atención o han sido reducidas a enumerar algunos datos económico/demográficos y algunas carácterísticas del tratamiento - generalmente la enumeración de los tipos de fármacos - consignándose muy escasa información detipo diagnóstica y de evolución del padecimiento, etc. La anamnesis médica casi ha desaparecido pese al reconocimiento técnico de su utilidad; es interesante al respecto observar como por ejemplo uno de los principal es especialistas mexicanos en alcoholismo (Velazco Fernández, 1980; 1981), asi como uno de los más destacados clínicos mundiales especializados en 
este padecimiento (G. Edwards, 1986; 1988) consideran decisiva la profundización de la indagación clínica especialmente para el paciente con alcoholismo crónico y/o dependiente, según lo cual hablan inclusive de la necesidad de desarrollar habilidades clínicas y existenciales especiales, para terminar asumiendo que ya no es posible realizarlas, pese a reconocer, sobre todo en el caso de Edwards, que la misma es decisiva para establecer un buen diagnóstico y orientar eficazmente el tratamiento. Antes de seguir con este análisis quiero indicar que no estoy proponiendo ningun lamento por formas perdidas de "humanismo médico", sino señalar algunas tendencias actuales de la biomedicina, que desarrollan aspectos contrarios o divergentes a los que la propia biomedicina y tambien las ciencias sociales consideran como óptimos en términos de la calidad de la atención.

Por lo tanto observamos la reducción del tiempo de la relación médico/paciente a través de la propia trayectoria histórica de la biomedicina, trayectoria que además indicaría que el médico ha ido abdicando de su propia posibilidad de detectar y analizar síntomas respecto de los padecimientos al referirlos cada vez más a indicadores objetivos. Actualmente la posibilidad de establecer diagnósticos y tratamientos no se depositan en el análisis de los síntomas, ni en los signos detectados por el "ojo" y "mano" clínicos, sino en los signos producidos por los diferentes tipos de analisis, es decir por pruebas objetivas, lo cual ha tenido consecuencias no sólo para la relación médico/paciente sino para la identificación profesional del médico consigo mismo (Reiser, 1978). Subrayo nuevamente que no niego ni rechazo la importancia de contar con indicadores diagnósticos objetivos, sino que estoy analizando las implicaciones que el desarrollo de determinados procesos pueden tener para la biomedicina y para la relación médico/paciente, las cuales no pueden ser observadas sino se incluye la dimensión histórica, que sin embargo aparece excluida frecuentemente de la reflexión y de la acción médica. Esta situación de exclusión de la dimensión histórica del saber médico adquiere características especiales si la referimos a lo que actualmente es el núcleo de la relación médico/paciente, es decir la prescripción del tratamiento, que en gran medida es la prescrición demedicamentos.

Desde la perspectiva que estamos desarrollando la inclusión de la dimensión histórica posibilitaria observar los beneficios de la pres- cripción de determinados fármacos para el abatimiento o control de determinados padecimientos, pero también los efectos negativos de los mismos, tanto en términos de un uso inmediato que evidencia una determinada eficacia, como en términos de un uso prolongado que evidencia que dicha eficacia es momentánea, 0 que su aplicación podría generar más problemas que los de su no utilización. Estos procesos no aparecen incluídos en la formación profesional ni en la práctica médica como aspectos reflexivos de su intervención, de tal manera que se genera un efecto interesante en la relación médico/paciente, según el cual el personal de salud suele achacar a la ignorancia, falta de educación y/o desidia de la población, lo que por lo menos en determinados casos fué consecuencia de un determinado uso médico original que la gente aprendió en forma directa o indirecta a través del propio personal de salud. Una simple y no demasiado profunda indagación histórica posibilitaría observar que algunas formas incorrrectas de utilizar los antibióticos, el disulfirán o el clorofenicol durante las décadas de los $50^{\prime}$ y $60^{\prime}$ los pacientes lo aprendieron del personal de salud; que el amamantamiento al seno materno fue cuestionado por parte del equipo de salud durante las mismas décadas sobre todo por razones de higiene einfluyó junto con otros factores en el reemplazo de la leche materna por las fórmulas lácteas, o que el consumo de ciertas drogas psicotrópicas actual mente consideradas adictivas fueron impulsadas por los tratamientos médicos inclusive desde la primera infancia respecto de una notable variedad de padecimientos que van desde las respiratorias agudas a la hiperkinesis. La aplicación de la dimensión histórica posibilitaría observar la gran cantidad de éxitos farmacológicos generados desde la biomedicina, pero también la cantidad de usos incorrectos que la población aprendió directa o indirectamemnte de la intervención médica, entre ellos el de la polifarmacia. Si bien este aspecto lo retomaremos luego al hablar de la automedicación, me interesa subrayar la exclusión de la dimensión histórica porque dicha exclusión cumple varias funciones, entre ellas la omisión de los efectos negativos no sólo de la prescripción médica, sino de su notoria influencia en el uso de la automedicación por la población. Lo cual, y lo recuerdo, no es un hecho del pasado, sino que sigue vigente, como es el caso del mal uso de anitibióticos por parte del personal de salud en los tratamientos de 
gastroenteritis como ha sido observado reiteradamente a través de estudios realizados recientemente en países subdesarrollados y desarrollados.

Tal vez los aspectos más excluídos por la biomedicina son los que corresponden al campo cultural; si bien el personal de salud suele hablar de la significación de la pobreza, del nivel de ingresos, de la calidad de la vivienda o del acceso al agua potable como factores que inciden en el proceso salud/enfermedad/atención (proceso s/e/a), sobre todo en los últimos años ha disminuido no tanto el reconocimiento sino la inclusión de los factores religiosos o de las creencias populares respecto del proceso s/e/a por parte de la biomedicina. M ientras hace unos cuarenta o cincuenta años, sobre todo la orientación salubrista, reparaba en la importancia de los factores culturales general mente como mecanismos negativos o como procesos que indicaban determinadas tendencias patologizantes en un grupo social determinado, dichos factores han sido cada vez más excluidos. En las décadas de los 40', 50' y 60' una parte del salubrismo reconocía que ciertas creencias culturales podían oponerse a la expansión biomédica, idea que opera en la actualidad por ejemplo respecto de los programas de planificación familiar o respecto del uso de protecciones en las relaciones sexuales, pero mientras en dichas décadas se pensaba como modificar culturalmente los saberes populares, actualmente se piensa a través de que mecanismos administrativos y médicos puede generarse esta modificación, para lo cual se proponen diferentes estrategias que van desde la estimulación económica al equipo de salud para elevar el número de mujeres "controladas", que incluye la aplicación de esterilizaciones femeninas y en menor frecuencia masculinas frecuentemente sin consentimiento informado; pasando por la aplicación de programas contra la pobreza donde la planificación familiar aparece como uno de los objetivos básicos de la solución de la misma 0 por lo menos de reducción de al gunas características consideradas simultán eamente como efecto/causa de la misma. Es decir que el equipo de salud y/o el de desarrollo social más que actuar sobre las condiciones culturales opera a través de acciones médicas o de estimulación económica

La dimensión cultural es cada vez menos utilizada salvo respecto de ciertos padecimientos, aunque debe subrayarse que los que más suelen tomarse en cuenta son los procesos so- ciales y no los culturales, aun en el caso del Sida 0 de las adicciones. En las décadas de los 50' y 60 ' toda una corriente epidemiológica se preocupó por detectar y establecer en América Latina cuales eran los patrones culturales de consumo de las sustancias adictivas, que en aquella época se centraba básicamente en el alcohol, lo cual contrasta con las tendencias epidemiológicas actuales respecto de las adicciones donde esta preocupación ha desaparecido y no ha sido reemplazada por ninguna otra búsqueda de factores y procesos culturales. De tal manera que por una parte los especialistas hablan de la importancia de los comportamientos culturales para la prevención de determinado problema, pero no se generan las investigaciones para obtener este tipo de información, y menos aun la aplicación de acciones de tipo cultural ( $\mathrm{Me}$ néndez y Di Pardo, 1996; 1999).

Pero tanto hace cuarenta años como en la actualidad el sentido fuerte de cómo la biomedicina utilizó y utiliza la dimensión cultural es de tipo negativo, es decir se observa sobre todo como dichos factores favorecen el desarrollo de padecimientos o se oponen a prácticas biomédicas que podrían abatirlos, pero no se incluyen las formas de atención "culturales" que podrían ser utilizadas favorablemente para abatir los daños. Si bien el uso de al gunas de estas formas de atención, sobre todo las consideradas "tradicionales", fue propuesta por las estrategias de atención primaria y se han generado investigaciones al respecto, las mismas han sido escasamente impulsadas por el sector salud, salvo en determinados contextos y sobre todo en función de una concepción de ampliación de cobertura a bajo costo y para poblaciones marginales rurales.

Es a través de tomar en cuenta los procesos y factores culturales, que podemos observar la existencia de otras formas de atención de la enfermedad, cuyas principales diferencias radican no sólo en el tipo de técnicas utilizadas sino en el sentido y significado cultural con que se las utiliza, residiendo en éllo gran parte de su función cultural más allá de su eficacia específica.

Podríamos seguir enumerando otros rasgos a través de los cuales observar procesos que explicarían el distanciamiento, subordinación o negación de otras formas de atención por parte de la biomedicina, pero para concluir con esta revisión sólo nos referiremos al último de los rasgos enumerados, es decir el que refiere a los criterios a través de los cuales la biomedicina se diferencia de la mayoria de las otras formas 
de atención. Si bien hay varios indicadores, el decisivo es el que refiere dicha diferenciación a principios de racionalidad científica, expresados sobre todo a través de la dimensión biológica. Y es en este rasgo donde se sintetizan a través de la autoidentificación profesional con "la ciencia", la exclusión de las otras formas identificadas justamente con criterios no científicos y con la dimensión cultural. Si bien la eficacia, la eficiencia o las condiciones de atención constituyen criterios importantes, el criterio decisivo refiere a la racionalidad científico/técnica.

El conjunto de estas y otras características del M M H, y no cada característica en si misma ( $M$ enéndez, 1990a) tiende a establecer una relación de hegemonía/subalternidad de la biomedicina respecto de las otras formas de atención no biomédicas, de tal manera que tiende a excluirlas, ignorarlas 0 a estigmatizarlas aunque también a una aceptación critica o inclusive a una apropiación o a un uso complementario sobre todo de ciertas técnicas, pero siempre con carácter subordinado.

Aclaro que no niego la importancia de la investigación biomédica, ni los aportes de la farmacología, ni la capacidad de detección diagnóstica a través de pruebas e indicadores objetivos, si no que lo que me interesa señalar es que éstas y otras características e instrumentos contribuyen a excluir, negar o secundarizar las otras formas de atención no biomédicas a través de criterios que sólo refieren a la dimensión científica del proceso s/e/a.

Este proceso adquiere un cariz especial en el caso de las relaciones que se establecen entre la biomedicina y la autoatención de los padeceres, debido a que éste se ha ido convirtiendo en uno de los campos relacionales más frecuentes, asi como aquel respecto del cual se generan tal vez más relaciones conflictivas tanto a nivel de la relación médico/paciente como de la relación sector salud/conjuntos sociales. Esto ocurre, como analizaremos de inmediato, por dos razones básicas; porque la autoatención es la forma de atención a la enfermedad más frecuente utilizada por los grupos sociales, y porque la autoatención es parte de la mayoria de los usos de las otras formas de atención, y en particular de la atención biomédica.

Estas afirmaciones que sustento a través de nuestras propias investigaciones y de estudios desarrollados por otros investigadores orientados por este enfoque ( $M$ enéndez, 1981; 1982; 1983; 1984; 1992; M endoza, 1994; Osorio, 1994;
Ortega, 1999) parten de considerar la autoatención a través de toda una serie de características que analizaré más adelante, pero sobre todo de observarla como proceso, lo cual se diferencia de las investigaciones generadas desde la biomedicina que la consideran como una entidad en sí y sólo referida a actividades muy específicas, lo cual conduce a un notorio subregistro de las actividades de autoatención inclusive en sus investigaciones específicas, y a no captar su papel constante y frecuentemente decisivo en el proceso de articulación de las diferentes formas de atención y especialmente con la biomedicina.

\section{Autoatención como proceso estructural}

La autoatención constituye una de las actividades básicas del proceso salud/enfermedad/ atención, siendo la actividad nuclear y sintetizadora desarrollada por los grupos sociales respecto de dicho proceso. La autoatención constituye una actividad constante aunque intermitente desarrollada a partir de los propios sujetos y grupos en forma autónoma o teniendo como referencia secundaria o decisiva a las otras formas de atención. La autoatención puede ser parte de las acciones desarrolladas por las otras formas, dado que frecuentemente es un paso necesario en la implementación de las mismas.

Por autoatención nos referimos en este trabajo a las representaciones y prácticas que la población utiliza a nivel de sujeto y grupo social para diagnosticar, explicar, atender, controlar, aliviar, aguantar, curar, solucionar o prevenir los procesos que afectan su salud en términos reales o imaginarios, sin la intervención central, directa e intencional de curadores profesionales, aun cuando estos pueden ser la referencia de la actividad de autoatención; de tal manera que la autoatención implica decidir la autoprescripción y el uso de un tratamiento en forma autónoma o relativamente autónoma. Es decir que la autoatención refiere a las representaciones y prácticas que manejan los sujetos y grupos respecto de sus padeceres, incluyendo las inducidas, prescriptas o propuestas por curadores de las diferentes formas de atención, pero que en función de cada proceso específico, de las condiciones sociales o de la situación de los sujetos conduce a que una parte de dicho proceso de prescripción y uso se autonomice, por lo menos en términos de autonomía relativa. 
Pero la autoatención puede ser pensada en dos niveles, uno amplio y otro restringido; el primer nivel refiere a todas las formas de autoatención que se requieren para asegurar la reproducción biosocial de los sujetos y grupos a nivel de los microgrupos y especialmente del grupo doméstico. Formas que son utilizadas a partir de los objetivos y normas establecidos por la propia cultura del grupo. Desde esta perspectiva podemos incluir no sólo la atención y prevención de los padecimientos, sino las actividades de preparación y distribución de alimentos, el aseo del hogar, del medio ambiente inmediato y del cuerpo, la obtención y uso de agua, ertc., etc., etc. Son parte de la autoatención el aprendizaje de la relación con la muerte en los diferentes términos prescriptos por cada cultura, que pueden incluir el cuidado del sujeto moribundo, el ayudar a morir, o el manejo del cadaver en función del sistema de creencias. La autoatención tal como la estamos definiendo, más allá de que ciertos actos se expresen fenoménicamente a través de individuos, refiere a microgrupos y especialmente a aquellos que más inciden en los procesos de reproducción biosocial y que incluyen sobre todo al grupo doméstico, pero tambien al grupo de trabajo, al grupo de adolescentes, etc., etc., etc.

La definición restringida refiere a las representaciones y prácticas aplicadas intencionalmente al proceso s/e/a. Por supuesto que es difícil establecer un claro corte entre al gunas actividades de la autoatención en sentido amplio y en sentido restringido, pero debemos asumir que este corte - como casi todo corte de tipo metodológico - opera como un mecanismo de ordenamiento de la realidad, y que en consecuencia dicho corte excluye - por supuesto que metodológicamente - determinados hechos, como por ejemplo la permeabilidad entre diferentes tipos de actividades. El corte metodológico posibilita concentrarnos justamente en la autoatención de tipo restringida, pues es la que nos interesa analizar, pero a partir de asumir que en los procesos concretos aparecerán incluidos aspectos de la autoatención ampliada.

La autoatención suele ser confundida o identificada por la biomedicina exclusivamente con la automedicación, es decir con la decisión más o menos autónoma de utilizar determinados fármacos para tratar determinados padecimientos sin intervención directa y/o inmediata del médico o del personal de salud habilitado para éllo. La automedicación sólo es parte de la autoatención, y el haber reducido la autoatención a automedicación es justamente un efecto del saber biomédico como veremos luego. En cosecuencia debe subrayarse que la automedicación no refiere sólo a la decisión de utilizar determinados tipos de fármacos desarrollados por la industria químico farmaceútica (IQF), sino a todas las sustancias(infusiones de hierbas, alcohol, marihuana, etc.), y para al gunos autores actividades de muy diferente tipo (cataplasmas, ventosas, masajes, etc.), que son decididas y usadas por los sujetos y microgrupos con autonomía relativa para actuar respecto de sus padeceres o para estimular determinados comportamientos. La biomedicina casi sólo piensa la automedicación a través de los fármacos producidos por la IQF, pero si bien ésta es actualmente la forma más extendida de automedicación en numerosos grupos sociales, no por éllo la automedicación refiere exclusivamenmte a éstos, sino que forma parte de las diferentes actividades de autoatención.

O tro término que se utiliza como equivalente de autoatención es el de "autocuidado", desarrollado desde la biomedicina y desde el salubrismo especialmente a partir del concepto estilo de vida, de tal manera que por autocuidado se suelen entender las acciones desarrolladas por los individuos para prevenir el desarrollo de ciertos padecimientos y para favorecer ciertos aspectos de salud positiva. El uso de este concepto por el sector salud es marcadamente individualista, y se diferencia del de autoatención cuyo carácter es básicamente grupal y social, pero lo importante a considerar aquí es que el concepto de autocuidado constituye una variante del de autoatención impulsado a través de determinadas ideologías no sólo técnicas sino sociales. En consecuencia las actividades de automedicación y autocuidado son parte del proceso de autoatención, pero no son equivalentes ya que autoatención constituye el concepto y proceso más inclusivo.

Aclaro que para al gunos autores el autocuidado tendría implicaciones básicamente preventivas o de potencializar la salud en términos de la denominada "salud positiva", y la autoatención referiría a acciones de tipo asistencial; mientras que para nosotros tanto la autoatención como el autocuidado pueden desarrollar ambos tipos de actividades, y la diferencia radica en el énfasis en lo individual impulsado por las políticas de autocuidado, mientras el concepto de autoatención refiere a la concepción de salud colectiva. Para esos autores sería 
el estilo de vida basado en el autocuidado individual el que posibilitaría reducir o eliminar conductas de riesgo respecto de fumar, beber excesi vamente alcohol o comer carnes rojas en abundantes cantidades, pero esta concepción de autocuidado y de estilo de vida suelen excluir en la práctica las condiciones de vida que hacen posible que dichas actividades de autocuidado y estilos de vida fracasen o sean exitosas ( M enéndez, 1998).

Dados nuestros objetivos me interesa recuperar lo ya señalado, que la biomedicina desarrolla sus críticas y oposiciones respecto de la autoatención casi exclusivamente en términos de automedicación. El personal de salud considera casi unanimemente que la automedicación es negativa o perniciosa; que es producto de la falta de educación o de la ignorancia, y tiende a identificarla como el comportamiento de los estratos sociales más bajos. Dicha evaluación surge generalmente de la propia experiencia clínica o de la tradición oral institucional, asi como de la posición del sector salud frente a la automedicación, pero no de investigaciones sistemáticas sobre lo negativo o beneficioso de la automedicación. En América Latina contamos con muy escasas investigaciones al respecto.

En general la biomedicina y el sector salud sólo han señalado los efectos negativos de la automedicación, denunciando recurrentemente su papel en el desarrollo de resistencias al efecto de ciertos medicamentos sobre los vectores de determinados padecimientos 0 a las consecuencias cancerígenas - o de otro tipo debido al uso indiscriminado de sustancias como el clorofenicol. Si bien la crítica a la automedicación es relativamente antigua, la misma se ha incrementado en las últimas décadas debido a que habría aumentado la automedicación con fármacos, y a que una parte de éstos tendrían consecuencias más negativas que los fármacos antiguos dadas las características "más agresivas" de las sustancias que los constituyen, a la especificidad del medicamento y a un uso cada vez más indiscriminado.

Pero más allá de que los cuestionamientos biomédicos sean o no correctos, me interesa subrayar la visión unilateralmente negativa de la biomedicina hacia la automedicación, asi como la noción de que la misma se ha incrementado; lo cual contrasta con las numerosas actividades de autoatención que ha impulsado el sector salud. Para nosotros la biomedicina ha desarrollado una relación contradictoria y es- cotomizante respecto del proceso de autoatención, dado que por una parte lo cuestiona en términos de automedicación, mientras por otra impulsa constantemente actividades de autocuidado y de otras formas de autoatención.

El análisis de estos procesos implica primero precisar algunos aspectos del proceso de autoatención. A partir de los aspectos señalados consideramos a la autoatención como un proceso estructural, constante aunque en continuo proceso de modificación. El caracter estructural de la autoatención, que implica que la misma se constituye como un proceso necesario en toda cultura a través de las acciones de los pequeños grupos para contribuir a asegurar el proceso de reproducción biosocial, deviene de algunos hechos básicos. Todo pequeño grupo, y en particular el grupo doméstico se caracteriza por la frecuencia, recurrencia y continuidad de episodios de enfermedades, padeceres, daños y/o problemas que afectan la salud de uno o más miembros de dichos microgrupos. La mayoría de estos episodios son leves, agudos y transitorios, y pueden hallar solución o por lo menos al ivio a través de las acciones de los miembros del grupo. Junto a estos padecimientos siempre han existido enfermedades crónicas que para que no se traduzcan en muerte prematura requieren que el sujeto y su microgrupo se constituyan en partes activas del proceso de atención, dado que sobre todo para algunos padecimientos la autoatención es decisiva.

El núcleo de la existencia y continuidad de la autoatención refiere a la frecuencia de padeceres agudos de muy diferente tipo, a la existencia e incremento de enfermedades crónicas físicas y mentales, a la búsqueda de estimulaciones con diferentes objetivos, de tal manera que toda sociedad necesita desarrollar saberes específicos a nivel de los grupos donde emergen estos padecimientos o estos objetivos de vida, estableciendo inclusive una división del trabajo especialmente en el grupo familiar donde la mujer en su rol de esposa/madre es la que se hace cargo del proceso s/e/a de los miembros del grupo. La mujer en dicho rol será la encargada de diagnosticar el padecimiento, de manejar por lo tanto indicadores diagnósticos, de establecer una evaluación de la gravedad o levedad del mismo; tendrá alguna noción de la evolución de los padeceres, asi como frecuentemente una noción de la variedad estacionaria de determinadas enfermedades. Será ella la que implemente los primeros tratamientos, asi co- 
mo decidirá por su cuenta o de acuerdo con otros miembros del grupos familiar la demanda de atención, que puede inciar por la consulta con personas de su inmediato espacio social, y continuar con el tipo de curador considerado más adecuado, y cuya consulta dependerá de los recursos económicos y culturales del grupo, y de la infraestructura de servicios existentes (Menéndez, 1982; 1984; 1990b; 1992; 1994). Para evitar equívocos, recuerdo que lo que describo es la fenomenología de la autoatención al interior del grupo doméstico, según la cual en todos los contextos culturales la autoatención de los padecimientos se desarrolla básicamente a través de la mujer en su rol de esposa/madre, sin por éllo considerar ninguna perpetuación de esta situación, sino subrayar que eso es lo que seguimos encontrando en nuestras sociades actuales.

La autoatención casi siempre es la primera actividad que el microgrupo realiza respecto de los padeceres detectados, y esa actividad no incluye inicialmente ningun curador profesional, aun cuando pueda inicialmente consultar a algun miembro de los espacios familiares y sociales inmediatos, pero que no desempeña ninguna actividad como curador profesional.

Es a partir de lo que acontece en la autoatención y por supuesto en la evolución del padecimiento, asi como en función de las condiciones sociales y culturales ya señaladas, que el sujeto y su microgrupo deciden consultar o no a curadores profesionales de una de las formas de atención que reconocen y aceptan. La decisión de ir a consultar a un curador profesional, y una parte de las actividades que se realizan luego de la consulta constituyen tambien parte del proceso de autoatención. Luego de la primera consulta puede decidirse la consulta inmediata o postergada con otro curador del mismo tipo o de otra forma de atención, y esta decision, al igual que lo que ocurre luego de la consulta también son parte de este proceso.

La decisión de consultar curadores profesionales se hace desde determinados saberes y determinadas experiencias que van a incidir en el tratamiento y en la relación curador/paciente. El sujeto y su grupo pueden consultar uno o más curadores y servicios, pero siempre a partir del núcleo de autoatención. De allí que la autoatención no debe ser pensada como un acto que los sujetos y grupos desarrollan aislada y autónomamente, sino como un proceso transaccional entre éstos y las diferentes formas de atención que operan como sus referentes. Más aun será el sujeto y su grupo los que a través de la carrera del enfermo articulen, a partir de las caracteristicas de cada grupo y de cada padecer, las diferentes formas de atención pero en función de esta experiencia. Es el proceso de autoatención el que articula las formas existentes, más allá de que éstas tengan interacciones directas entre sí. La mayoría de las formas de atención, incluida la biomédica, permanece frecuentemente ignorante de una carrera del enfermo que articula diferentes formas y hasta sistemas de atención con el objetivo de hallar una solución a sus problemas. Esto es en gran medida debido a que la realidad social es pensada y analizada como acto y no como proceso; la autoatención es potencialmente siempre parte de un proceso que incluye no sólo los actos de los sujetos y microgrupos, sino de los diferentes curadores que intervienen en dicho proceso. La tendencia a-relacional que ha dominado el estudio del proceso salud/enfermedad/ atención tiende a colocar el acento sobre cada actor en sí, en lugar de colocarlo sobre el proceso relacional que incluye todos los actores significativos que intervienen en el mismo.

El conjunto de las actividades y articulaciones que estamos señalando se dan potencialmente en todo grupo y sujeto más allá de su nivel educacional y económico, aunque éstos y otros factores - como ya vimos - inciden en las características específicas que tendrá el proceso de atención. No cabe duda que la gravedad 0 agravamiento de una enfermedad, la complejidad de la misma, la necesidad de aplicar tecnologías sofisticadas, la existencia o no de cobertura de las diferentes formas de atención, la pertenencia a algún sistema de seguridad social incidirán en el tipo de atención y autoatención desarrollado. Pero un aspecto decisivo es que la autoatención se constituye estructuralmente no sólo por las razones señaladas, sino porque implica la acción más racional, en términos culturales, de estrategia de supervivencia e inclusive de costo/beneficio no sólo ecónómicos, sino de tiempo por parte del grupo, en la medida que asumamos en toda su envergadura la incidencia y significación que tienen para su vida cotidiana la frecuencia y recurrencia de los diferentes tipos de padeceres que amenazan real o imaginariamente a los sujetos y microgrupos.

D esde esta perspectiva y para tener noción cabal de lo que estamos proponiendo, debo precisar que cuando hablamos de padeceres nos estamos refiriendo a una extensa variedad que va desde dolores episódicos de cabeza, dolores musculares leves, temperaturas poco elevadas, resfrios o escozores transitorios, pa- 
sando por dolores del alma, estados de tristeza, ansiedades, o pesares momentáneos. Toda una serie de dolores devenidos de golpes, accidentes o relaciones sociales operan durante parte del día o la semana en algunos de nosotros. Es decir que hay toda una serie de padeceres que el sujeto experimenta y autoatiende de alguna manera a través de cada día. Respecto de estos padeceres, puede no hacer nada, o sólo hablarlo con alguién, dejando que el trascurso del tiempo lo solucione, lo cual también es parte de las acciones de autoatención. Todos estos padeceres son atendidos y solucionados a través de la autoatención, a menos que se agraven o que su reiteración y/o continuidad preocupe al sujeto y su grupo. Debemos recordar que en la primera infancia al gunas enfermedades gastrointestinal es y respiratorias agudas, así como al gunos padecimientos populares y tradicionales son constantes, y también tienden a ser atendidos al interior del grupo, y solo se pasa a consulta con un curador cuando cobra determinado nivel de gravedad establecido por el propio grupo.

Pero además de estos padecimientos el paso a primer plano de las enfermedades crónicas y de las invalideces ha conducido a que parte del tratamiento de las mismas sea implementado por el enfermo y/o por su grupo, dado que si no lo hace se reducirá singnificativamente su esperanza de vida. De tal manera que la mayoría de las acciones respecto de los padecimientos agudos y crónicos se realizan en forma autónoma 0 articulada con otras formas de atención, a través de la autoatención.

El conjunto de estas acciones supone la existencia de un saber respecto del proceso s/e/a dentro de los microgrupos y especial mente de los grupos domésticos, que más allá de lo erróneo o correcto de sus explicaciones causales, diagnósticos provisorios o tipo de tratamiento, implica sobre todo la existencia de este saber, que se ejercita constantemente a través de diferentes tipos de padeceres, y es a partir de este saber que se establecen las relaciones transaccionales con las otras formas de atención. Cuando un sujeto va al médico, a un quiropráctico, a una curandera o a un sanador new age va generalmente con un diagnóstico provisional del padecimiento por el cual recurre a dicho curador. Y lo que subrayo, más allá de lo equivocado o certero del diagnóstico asi como de lo preciso o difuso del mismo, es la existencia de esta actividad diagnóstica ejercida por el propio sujeto y su microgrupo.
Pero la autoatención y la automedicación no refieren sólo a la intervención sobre los padeceres, sino también deben ser referidas a la aplicación de tratamientos, al consumo de sustancias 0 a la realización de actividades que, según los que las usan, posibiltarían un mejor desempeño deportivo, sexual o laboral. Son sustancias y acciones que no sólo posibilitarían salir de la angustia, de la depresión o del dolor, sino que permitirían ciertos rendimientos y goces. D esde esta perspectiva las diferentes formas de adicción pueden ser consideradas parte del proceso de autoatención ( $M$ enéndez, 1982; 1990b; Romani y Comelles, 1991; Szasz, 1979a; 1979b). M ás aun toda una serie de actividades impulsadas sobre todo en los últimos años y relacionadas con el desarrollo de ciertos estilos de vida, tratan de obtener determinados beneficios físicos y mentales a través de correr todas las mañanas, o todas las tardes - dados que las noches se han tornado peligrosas -, de ir dia por medio al gimnasio, de beber entre tres y cuatro litros de agua diario, de practicar yoga 0 de realizar ciertos ejercicos zem.

Desde la perspectiva que estamos desarrollando la automedicación refiere no sólo al consumo autónomo de asprinas, antibióticos 0 psicotrópicos en calidad de fármacos, sino que refiere al consumo de anabólicos, de infusiones de boldo o de tila o del consumo de alcohol en determinadas situaciones. Será la intencionalidad con que se utilice cualquiera de estas sustancias las que le de el carácter de automedicación.

$\mathrm{H}$ ay toda una serie de procesos sociales, económicos e ideológicos que han impulsado determinadas formas de autoatención en las sociedades actuales. Generalmente se sostiene que el desarrollo de la industria químico/farmaceútica y la publicidad tienen que ver centralmente con esta tendencia al consumo de determinados productos; también se ha señalado que el desarrollo de determinadas ideologías en busca de una salud y juventud más o menos permanente, o de ciertos equilibrios psicofísicos ligados o no a concepciones religiosas y/o consumistas han impulsado determinadas formas de autoatención y automedicación. Pero también toda una serie de grupos organizados a partir de un padecimiento (Alcohólicos Anónimos, N euróticos Anónimos, Clubes de Diabéticos, etc.) o desarrollados a partir de reivindicar su identidad diferencial (movimiento feminista, movimiento gay) ha impulsado procesos y técnicas de autoatención, de tal manera 
que debemos reconocer la existencia de muy diferentes sectores sociales y de objetivos personales que potencian la autoatención, incluida la automedicación.

\section{La biomedicina como generadora de autoatención}

H emos tratado de demostrar en este trabajo que hay una intensa y constante relación entre las actividades biomédicas y las de autoatención a partir de procesos impulsados sobre todo por las necesidades, objetivos y/o deseos de los sujetos y grupos. Si bien cada grupo incluye en sus actividades de autoatención explicaciones y sobre todo prácticas y productos devenidos de diferentes fuentes, debe asumirse que la biomedicina constituye actual mente una de las principales fuentes, según algunos autores la principal, de las actividades de autoatención.

Hemos señalado además que la biomedicina cuestiona y/o ve negativamente a la automedicación, a la que considera responsable de toda una serie de consecuencias negativas, pero que simultáneamente la biomedicina considera positivamente el autocuidado y genera toda una serie de actividades que impulsan no sólo el autocuidado sino tambien la automedicación. Y asi observamos que en la mayoria de los países de América Latina el sector salud desarrolla programas de planificación familiar, o si se prefiere de salud reproductiva, que tratan de que el grupo familiar y sobre todo la mujer aprenda a planificar, utilice varios métodos y especialmente la píldora anticonceptiva, y que sobre todo los utilice autonomamente.

El sector salud y toda una variedad de organizaciones no gubernamentales (ONG) han difundido el uso autónomo de la rehidratación oral, enseñando inclusive a preparar dicha solución, dado el papel decisivo que cumple en el control y abatimiento de diversos tipos de gastroenteritis. El objetivo es lograr también que las personas autonomicen la preparación o la compra y su uso. El SS y otros grupos han promovido intensamente el uso del condón no sólo como técnica anticonceptiva, sino como mecanismo preventivo respecto de enfermedades de transmisión sexual, que los sujetos deberían decidir autónoma y/o relacionadamente.

En algunos países el SS está tratando que la población pueda detectar determinados problemas, dado que una detección oportuna po- sibilitaria una intervención médica más eficaz. Por lo tanto se sugiere o induce a que los varones se hagan cada seis meses o un año medición del antígeno prostatico, y las mujeres realicen papanicolau u otras formas más sosfisticadas de detección de determinados padecimientos. EI SS y sobre todo determinadas ONG promueven que las mujeres aprendan a palpar sus senos, para detectar tambien problemas que posibiliten una intervención oportuna. En el caso de ONG de orientación feminista han enseñado a las mujeres a usar el espejo vaginal, asi como el uso de otros instrumentos y saberes que les permita proteger su cuerpo.

Es la propia biomedi cina la que para determinadas enfermedades crónicas ha impulsado las acciones autónomas de los pacientes, de tal manera que aprendan a leer glucosa en orina y/o sangre a través de técnicas sencillas, así como a aprender a autoinyectarse insulina. Despues de que durante años la biomedicina cuestionara o ignorara el papel de los grupos de Alcohólicos Anónimos, actualmente en numerosos contextos el SS ha reconocido a los grupos de AA como parte central del tratamiento contra el alcoholismo, y aconseja a los "al cohólicos rehabilitados" su permanencia en dichos grupos como principal mecanismo de control de dicho padecimiento, dada la alta frecuencia de recaidas que caracterizan no sólo al consumo de al cohol, sino al conjunto de los comportamientos adictivos.

Es decir que por un lado la biomedicina y el sector salud cuestionan la automedicación, y por otro impulsan, favorecen, incluyen o aceptan formas de autoatención, incluidos ciertos tipos de automedicación. M ás aun varias de las actividades señaladas evidencian que la propia biomedicina es conciente de las actividades de articulación que se generan sobre todo en el caso de las enfermedades crónicas. En consecuencia domina en la biomedicina una especie de escotomización respecto del proceso de autoatención, en términos de escindir la autoatención considerada "buena" de la "mala”, no asumiendo que ambas son parte de un mismo proceso, y que tienen los mismos objetivos desde las decisiones y acciones de los grupos sociales. Esta manera de pensar la autoatención por el SS contribuye por una parte a seguir responsabilizando a la "víctima" de los problemas que la aquejan, pero en este caso la responsabiliza negativamente de las soluciones que ha ideado a través de las diferentes formas de autoatenderse. 
El sector salud debe asumir que la autoatención no sólo es la principal forma de atención desarrollada por los propios conjuntos sociales, sino que es a través de ella que los sujetos y grupos se relacionan con las otras formas de atención, incluída la biomedicina. Es a través de la autoatención que los sujetos se apropian de las otras formas y las relacionan, y es en este proceso que se generan consecuencias negativas y positivas para la salud. Cuando nosotros recuperamos como básica la autoatención, no supone que pensemos que la misma es siempre acertada y eficaz; por el contrario pensamos que una parte sustantiva de la misma no sabemos cuanto por falta de investigaciones específicas - tiene consecuencias negativas 0 por lo menos resultados ineficaces.

Pero la autoatención no implica sólo la posibilidad de consecuencias negativas o positivas para la salud, sino que es el medio a través del cual los sujetos y sus grupos evidencian su capacidad de acción, de creatividad, de encontrar soluciones, y en consecuencia es un mecanismo potencial - y subrayo lo de potencial de afianzamiento de ciertos micropoderes, asi como de la validez de sus propios saberes. Subrayo lo de potencial, porque algunos autores colocan en el ejercicio de estos micropoderes la posibilidad de un desarrollo más global del poder, que por lo menos es dudoso.

El proceso de autoatención se desarrolla actualmente en gran medida a través de la relación directa e indirecta con la biomedicina. Este es un proceso dinámico y cambiante, que permite observar que procesos de autoatención que durante un tiempo fueron cuestionados ahora son aceptados como comportamientos "naturales". ¿Quién se asombra o cuestiona actualmente que las personas utilicen el termómetro para medir su temperatura? El termómetro forma parte del equipamiento básico de gran parte de la población de determinados países "occidentales", pero este uso es parte de un proceso de apropiación ya olvidado. Sin embargo actualmente otras apropiaciones tecnológicas por los sujetos y grupos son cuestionadas en nombre de la complejidad técnica y científica.

El tipo de relación dinámica, complementaria, pero tambien simultáneamente conflictiva y contradictoria entre biomedicina y los sujetos y grupos sociales, puede observarse especial mente a través de uno de los principales actos médicos, el del tratamiento y especialmente el de la prescripción de medicamentos.
Lo que acontece en torno a la precripción médica y el cumplimiento de la misma se constituye en uno de los principales campos de crítica de la biomedicina hacia el comportamiento de la población, concluyendo reiteradamente que la población no comprende la prescripción, no la cumple o la cumple mal. Constantemente se señala que el paciente no completa la totalidad del tratamiento, ya que por decisión propia lo interrumpe frecuentemente cuando él decide que ya ha sido eficaz, que ya se ha solucionado su problema.

La mayoría de estos señalamientos pueden ser correctos, y existen varias explicaciones al respecto, pero me interesa recuperar un tipo de comportamiento caracterizado por el no cumplimiento de la prescripción, el cual se ha ido evidenciando en los últimos años y que se conoce como el caso del "paciente bien informado" (Donovan y Blake, 1992). Este se caracteriza por no cumplir la prescripción, pero no por ignorancia de las consecuencias negativas que puede tener la suspensión o modificación del tratamiento o por no entender la prescripción recetada, si no debido a dos hechos básicos, por una parte a la cantidad de información técnica que posee este tipo de paciente y por otra a que su modificación del tratamiento obedece a la experiencia de su propio cuerpo con el tratamiento recetado. De tal manera que el paciente decide aumentar, reducir la dosis o espaciarla según su conocimiento y su propia experiencia; acciones que el paciente no oculta sino que discute con el médico. Este paciente, y lo subrayo, no cuestiona el "poder médico" ni la eficacia de la biomedicina; todo lo contrario es un partidario de la misma; a este paciente no le interesa discutir el poder en la relación médico/ paciente, sino mejorar su salud, controlar lo mejor posible su padecimiento crónico. Este nuevo tipo de paciente - que por supuesto no es tan nuevo - se caracteriza por su saber y no por su ignorancia, pero además por una información que refiere a su propia experiencia de enfermedad y atención.

Actualmente este tipo de situaciones constituye una de las mejores expresiones de la relación dinámica que opera entre la biomedicina y el proceso de autoatención a partir de las acciones impulsadas por los sujetos y grupos en función de su propia enfermedad, lo que está dando lugar al desarrollo de propuestas de co-atención. 


\section{Propuestas relacionales}

A lo largo de este texto hemos querido subrayar no sólo el peso decisivo de la autoatención, sino la existencia de relaciones de diferente tipo entre ésta y las actividades biomédicas, y que en consecuencia y más allá del reconocimiento de los aspectos potencialmente negativos de la autoatención, en lugar de cuestionarla constantemente, de estigmatizarla, de negarla e inclusive de intentar prohibir la adquicisión de medicamentos, el SS debería tratar intencionalmente de utilizarla, no sólo por su potencial eficacia, sino porque dicha forma de atención puede ser prohibida pero no eliminada, debido a las características descriptas previamente, y especialmente al papel que cumple en el proceso de reproducción biosocial ( $M$ enéndez, 1982; 1983; 1990b; 1992).

Ya hemos señalado que la autoatención constituye el primer nivel real de atención, y que dicho proceso cuestiona algunos de los principales estereotipos que maneja el SS respecto de los conjuntos sociales. La autoatención evidencia que si bien los sujetos y grupos se equivocan, usan incorrectamente los medicamentos, etc., también evidencia que los mismos aprenden, modifican, resignifican sus prácticas, y que una parte de esa automedicación ha sido decisiva para abatir o controlar determinados padecimientos. Y esto no sólo por un efecto mágico o de micropoder de la relación médico/paciente o del fármaco, sino por una apropiación y uso que evidencia en la propia experiencia del sujeto y su grupo que el fármaco consumido es eficaz o por lo menos más eficaz que otros productos. El hecho deque la población utilice estos fármacos e inclusive autonomice su uso, evidencia que reconoce su eficacia y además, y es lo que me interesa subrayar, que en gran medida aprende dicha eficacia a través de la relación directa o indirecta con el personal de salud. Esta conclusión no niega, por supuesto, que en la relación médico/paciente se desarrollen efectos de micropoder, ni que el fármaco y el propio médico tengan una eficacia simbólica que va más allá de la eficacia intrínseca del fármaco.

El proceso de autoatención evidencia no sólo que la gente se apropia y aprende, sino que el SS, el personal de salud, el médico enseñan a autoatenderse más allá de la intencionalidad de hacerlo. Los sujetos y grupos aprenden constantemente el uso de indicadores diagnósticos y de fármacos a través de la relación médico/pa- ciente, aun dentro del reducido tiempo que caracteriza la consulta médica actual. Gran parte del mayor y profundo aprendizaje opera en el momento clínico, pues es el momento en que se constituyen aperturas afectivas y cognitivas para poder asumir lo prescripto de una manera experiencial.

En consecuencia el SS debería impulsar intencionalmente la articulación entre los servicios de salud y el proceso de autoatención, de tal manera que se constituyera en parte central de sus estrategias. Por supuesto que en la práctica el SS ha ido impulsando al gunas articulaciones como hemos visto, pero conjuntamente sigue manteniendo una crítica a determinadas formas de autatención, y sigue estigmatizando la automedicación. Lo que nosotros proponemos no es eliminar la crítica, sino fundamentarla; pero lo más importante para nosotros es tratar de mejorar los comportamientos de autoatención, que los conjunto sociales casi inevitablemente desarrollarán a través de una reorientación de las acciones de educación para la salud, pero no sólo de las acciones que especificamente se denominan así, sino de lo que se procesa en la relación médico/paciente. El SS debería enseñar a automedicarse bien a la población y no sólo a "autocuidarse", lo cual implica el desarrollo de una relación médico/paciente más simétrica y complementaria. Para éllo deberían modificarse varias prácticas y representaciones profesionales e institucionales, y en particular que el sector salud y el personal de salud asumieran que la autoatención no es un proceso aislado u opuesto al quehacer médico, sino que es parte integral del proceso $\mathrm{s} / \mathrm{e} / \mathrm{a}$ que incluye a ambos. En consecuencia de bería abandonar una actitud escotomizante de la realidad, a partir de impulsar un saber relacional de la misma.

Por último quiero aclarar que nuestro énfasis en la autoatención no supone eliminar ni menguar la responsabilidad del Estado respecto de las acciones contra la enfermedad; no supone reducir las inversiones en el campo de la s/e/a, ni implica reducir el papel de los servicios de salud para colocarlos exclusivamente en la sociedad civil, que es una forma elegante de pensar la privatización por lo menos por algunas tendencias. Si bien ésta ha sido la manera en que al gunos sistemas de salud han impulsado su reforma a través de la privatización directa o indirecta de los servicios de salud, que en algunos casos supone darle un papel especial a las ONG, en función de una relación cos- 
to/beneficio que posibilita abaratar costos de atención a la enfermedad, y arguyendo que esta orientación reconoce el peso de la sociedad civil, nuestra propuesta obviamente no va en esa dirección. Proponemos la inclusión protagónica de los grupos y sujetos sociales a través de la autoatención - y por supuesto de otros procesos y mecanismos -, pero articulada con los servicios de salud biomédicos y con las otras formas de atención, lo cual implica incluir la responsabilidad económica y social del Estado tanto respecto de los servicios de salud como hacia los grupos y sujetos, pero con el objetivo de impulsar la articulación intencional de un proceso que hasta ahora está básicamente depositado en los sujetos y grupos sociales, así como para incrementar la eficacia del mismo y de ser posible reforzar la capacidad y autonomía de dichos grupos sin abdicar de la responsabilidad del Estado, y sin encontrar en esta propuesta ninguna contradicción en sus términos como sostienen algunas tendencias neoliberales y no tan liberales.

Lo que debemos asumir en términos críticos de tipo epistemológico y en términos lo más claro posible de acciones técnicas y sociales es que determinados conceptos, procesos y sujetos sociales pueden ser apropiados y/o utilizados por tendencias técnico/ideológicas que sostienen concepciones muy diversas, que impulsan propuestas diferentes y hasta opuestas en- tre sí. Frente a éllo nuestra actitud epistemológica no debe ser incluir dentro de un mismo bloque social a todas las tendencias que utilizan conceptos similares, se preocupan por los mismos problemas y trabajan sobre ciertos sujetos sociales, sino por el contrario debemos producir un análisis teórico y práctico que aclare la especificidad, orientación y dinámica de las diferentes propuestas. Este proceso se convierte en necesario, cuando observamos que en el caso de la autoatención, y más aun en el dela autogestión, se desarrollan tendencias que impulsan dichos conceptos y procesos a través de lo que se denomina autocuidado en un sentido opuesto o por lo menos diferente del que estamos proponiendo. Como lo hemos señalado en otros trabajos ( $M$ enéndez, 1981; 1982; 1983; 1990a; 1994), la inclusión de las diferentes formas de atención dentro de las relaciones de hegemonía/subalternidad que operan en un contexto determinado posibilita analizar dinámicamente las transacciones que se desarrollan entre los diferentes actores sociales, y en consecuencia encontrar en sus prácticas el sentido y la orientación de sus saberes. El papel de la biomedicina, de la autoatención o de la herbolaria no se define a priori en función de las características de cada saber tomado en forma aislada, sino a través de las consecuencias de sus saberes en las condiciones de salud y de vida de los conjuntos sociales estratificados.

\section{Referencias bibliográficas}

Cárdenas R 2000. La práctica de la cesárea en las áreas urbanas de M éxico, pp. 301-28. In C Stern \& Echarri C (comps.). Salud reproductiva y sociedad. Resultados de investigación. El Colegio de M éxico, M éxico.

Conrad P 1976. Identifyng hyperactive children. Lexington Books, Lexington.

Conrad P \& Schneider J 1980. Deviance and medicalization. From badness to sickness. The C. V. M osby, St. Louis.

Donovan JL \& Blacke DR 1992. Patient non-compliance: deviance or reasonal decision-making? Social Science \& M edicine 34(5):507-513.

Edwards G 1986. Tratamiento de alcohólicos. Guía para el ayudante profesional. Trillas, M éxico 
Edwards G 1988. Tratamientos. Boletín de la Organización Panamericana de la Salud 104(3):273-82.

Good B 1994. M edicine, rationality and experience. An anthropological perspective. Cambridge University Press, Cambridge.

Good B \& Del Vecchio Good M -J 1993. Learning medicine': the construction of medical knowwledge at H arvard M edical School, pp. 81-107. In Lindenbaum y M Lock(edits.). Knowledge, power and practice.University of California Press, Berkeley.

Kleinman A 1988a. The illness narratives. Sufferings, healing and the human condition. Basic Books, N ew York.

Kleinman A 1988b. Rethinking psychiatry: from cultural categorie to personal experience. The Free Press, New York.

M endoza Z 1994. De lo biomédico a lo popular: el proceso salud/enfermedad/atención en San Juan Copala, Oaxaca. Tesis de maestría de la Escuela $\mathrm{N}$ acional de Antropología e Historia, M éxico.

M enéndez EL 1978. El modelo médico y la salud de los trabajadores, pp. 11-53. In F Basaglia et al. La salud de los trabajadores. A portes para una política de la salud. Editorial Nueva Imagen, M éxico.

M enéndez EL1979. Cura y control. Editorial Nueva Imagen, M éxico.

M enéndez EL 1981. Poder, estratificación y salud. Análisis de las condiciones sociales y económicas de la enfermedad en Yucatán. Ediciones de la Casa Chata, M éxico.

M enéndez EL 1982. Autoatención y automedicación, un sistema de transacciones sociales permanentes, $\mathrm{pp}$. 4-52. In EL M enéndez (edit.). M edios de comunicación masiva, reproducción familiar y formas de medicina popular. Casa Chata/CIESAS, M éxico.

$M$ enéndez EL 1983. H acia una práctica médica alternativa. H egemonía y autoatención (gestión) en salud. Casa Chata-Ciesas, M éxico.

M enéndez EL 1984. Descripción y análisis de las representaciones y prácticas de grupos domésticos sobre la mortalidad en niños menores de cinco años en una comunidad de Guanajuato. M inisterio de Salud, M éxico.

M enéndez EL 1990a. M orir de alcohol. Saber y hegemonía médica. Alianza Editorial M exicana, M éxico.

M enéndez EL 1990b. Antropología médica. Orientaciones, desigualdades y transacciones. Casa Chata-Ciesas, M éxico.

M enéndez EL1992a. Grupo doméstico y proceso salud/ enfermedad/atención. Del treoricismo al movimiento continuo. Cuadernos M édico-Sociales 59:3-18.

M enéndez EL1994. La enfermedad y la curación. ¿Qué es medicina tradicional? Alteridades 4(7):71-83.

M enéndez EL 1997. El punto de vista del actor. Homogeneidad, diferencia e historicidad. Relaciones 69:237271
M enéndez EL 1998. Estilos de vida, riesgos y construc ción social. Conceptos similares y significados diferentes. Estudios Sociológicos 46:37-67.

M enéndez EL 2000. Factores culturales: de las definiciones a los usos específicos, pp. 163-88. In E Perdiguero \& JM Comelles (eds.). M edicina y cultura. Estudios entre la antropología y la medicina. Edicións Bellaterra, Barcelona.

$M$ enéndez EL 2002. La parte negada de la cultura. Edicións Bellaterra, Barcelona.

M enéndez EL (edit.) 1982. M edios de comunicación masiva, reproducción familiar y formas de medicina popular. Casa Chata-Ciesas, M éxico.

M enéndez EL \& Di Pardo R 1996. De algunos alcoholismos y algunos saberes. Colecc. M. Othon de M endizabal, Ciesas, M éxico.

M enéndez EL \& Di Pardo R 1999. M odelo médico hege mónico y alcoholismo: psiquiatras, epidemiólogos y educadores. M inisterio de Salud, M éxico.

M enéndez EL \& Ramirez S 1980. Producción social y reproducción ideológógica de los procesos de salud/ enfermedad en una comunidad yucateca. M inisterio de Salud, M éxico.

Ortega J 1999. Proceso reproductivo femenino: saberes, género y generaciones en una comunidad maya de Yucatán. Tesis de doctorado en antropología, El Colegio de M ichoacán, Zamora, M éxico.

Osorio RM 1994. La cultura médica materna y la salud infantil. Tesis de maestría, Escuela N acional de Antropología e Historia, M éxico.

Reiser SJ 1978. M edicine and the reign of technology. Cambridge U niversity Press, Boston.

Romani O \& Comelles JM 1991. Les contradictions dans l'usage des psychotropes dans les societés contemporaines: automedication et dependance. Psychotropes VI(3):39-57.

Szasz Th, Savitt RA \& TomásJ 1979. Editorial. Psicología del drogadicto. Rodolfo Alonso, Buenos Aires.

Szasz Th 1979a. La función del mecanismo contrafóbico en la adicción, pp. 9-41. In Th Szasz, R Savitt \& J Tomas. Psiocología del drogadicto. Editorial Rodolfo Alonso, Buenos Aires.

Szasz Th 1979b. La ética de la adicción, pp. 89-111. In Th Szasz, R Savitt \& J Tomas. Psicología del drogadicto. Editorial Rodolfo Alonso, Buenos Aires.

Trotter R \& Chavira JA 1981. Curanderimo: Mexican American folk healing. The University of GeorgiaPress, Georgia

Velazco Fernández R 1980. Salud mental, enfermedad mental y alcoholismo. Anuies, M éxico.

Velazco Fernández R 1981. Esa enfermedad Ilamada alcoholismo. Trillas, M éxico.

Artigo apresentado em 23/8/2002

Aprovado em 25/10/2002

Versão final apresentada em 5/12/002 